\title{
AUSENCIAS INVISIBLES. MUJERES ARTISTAS \\ EN LAS FERIAS DE ARTE CONTEMPORÁNEO
}

\section{INVISIBLE ABSENCES. WOMEN ARTISTS AT CONTEMPORARY ART FAIRS}

\author{
Joan Feliu Franch \\ Universitat Jaume I de Castelló
}

\section{RESUMEN}

La naturalidad con la que se asume la ausencia de las mujeres en la cultura supone una doble discriminación. Sus creaciones son invisibilizadas en las ferias de arte contemporáneo y dichas ausencias a su vez resultan invisibles. Es necesaria, especialmente en las ferias con aporte de dinero público, ejecutar una política cultural que posibilite la inclusión de las mujeres artistas como reflejo de una realidad social donde sí son protagonistas.

Palabras Clave: arte contemporáneo, feria, mujeres artistas, mercado, paridad.

\section{ABSTRACT}

The naturalness with which the absence of women from culture is assumed supposes a double discrimination. Their creations are invisible in contemporary art fairs and these absences in turn are out of sight. It is necessary, especially in fairs carried out with the contribution of public money, to execute a cultural policy that allows the inclusion of women artists as a reflection of a social reality where, yes, they are protagonists.

Keywords: Contemporary Art, Fair, Women Artists, Market, Parity.

Las autoridades públicas, en el ámbito de sus competencias, velarán por hacer efectivo el principio de igualdad de trato y de oportunidades entre mujeres y hombres en todo lo concerniente a la creación y producción artística e intelectual y a la difusión de la misma». Así comienza el Artículo 26 de la Ley de Igualdad'. Vamos a tener presente esta redacción a lo largo de este artículo. 
Más allá de números astronómicos y subastas enloquecidas, el mercado del arte encuentra su escenificación en las ferias. Nacionales o internacionales, son una muestra de lo relevante del arte contemporáneo del momento, y sirven para que se conozca, se aprecie y se venda, para que se difunda el arte como parte de una cultura que debe perdurar.

Una visita a cualquier feria de arte contemporáneo nos atestigua el interés del público femenino. No hemos encontrado cifras en ese sentido, pero es una obviedad constatar la presencia de mujeres a las que les interesan este tipo de eventos, como en el ejemplo de la imagen que se muestra, tomada entre el público, al azar, de la Feria Marte [Fig. 1]. Es lógico, pues la mayoría de los estudiantes formados en carreras encaminadas a la creación son mujeres (según el INE): en Bellas Artes suponen un 65\% del total de alumnos, y un $74 \%$ en Historia del Arte. También resulta significativa la presencia de mujeres en la dirección de galerías de arte y como conservadoras y curadoras de exposiciones, hecho que no tiene una correspondencia con la participación de mujeres artistas en las exposiciones de estos mismos espacios.

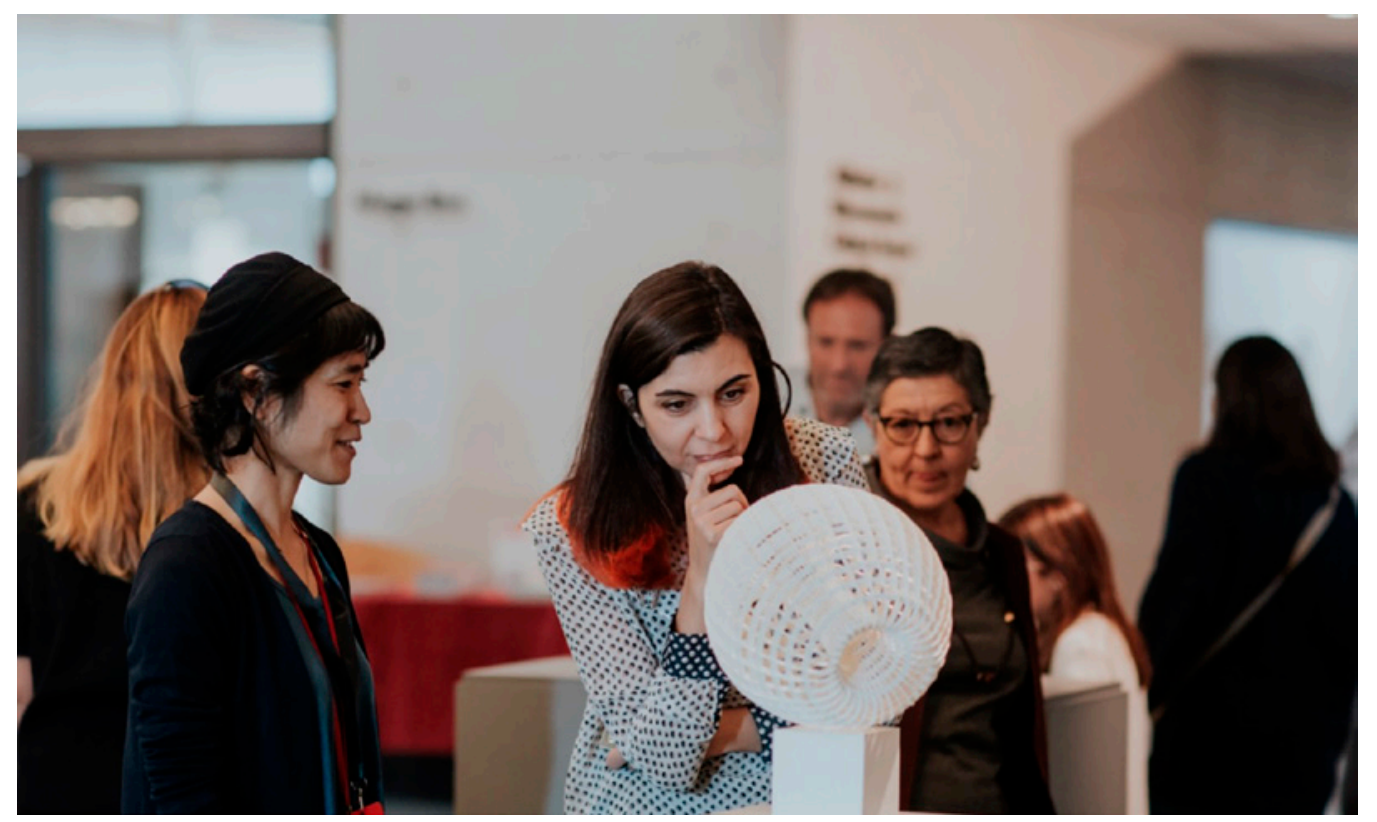

Fig. 1. Público (mayoritariamente femenino) en la feria Marte, 2017. Fotografía: Marcos Amuedo. 


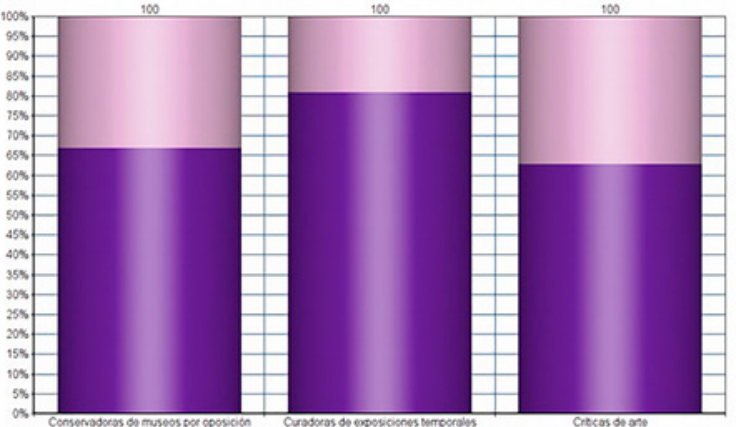

Gráfica 1. Mujeres en profesiones vinculadas a la gestión artística.

Fuente: Centro de Documentación de Mujeres en las Artes Visuales. Elaboración propia.

Así, según los estudios del Centro de Documentación de Mujeres en las Artes Visuales, la curaduría de exposiciones temporales está prácticamente copada por profesionales mujeres $(81 \%)$, y son mayoría las conservadoras de museos con plaza por oposición (67\%) y las críticas de arte (63\%) [Gráf. 1]. A estos datos podríamos añadir la práctica paridad en cuanto a direcciones de galerías, sin embargo, solo un $16 \%$ de las profesionales que ejercen la crítica escrita en grandes medios de prensa son mujeres; solo un $22 \%$ son directoras de museos o centros de arte contemporáneos; y sólo un 13\% de las obras que se muestran son de mujeres [Gráf. 2].

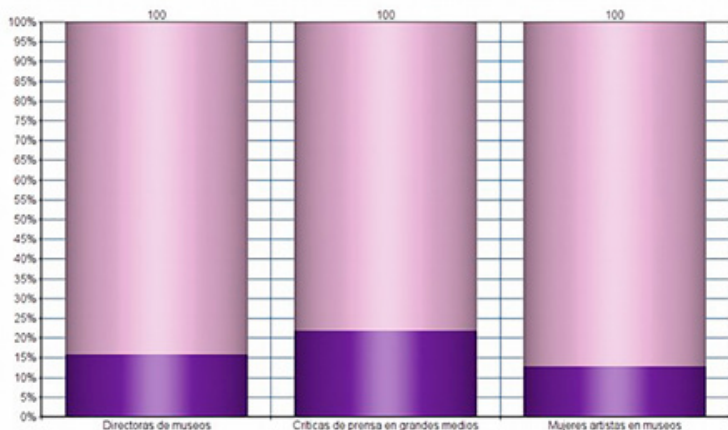

Gráfica 2. Directoras de museos y centros de arte contemporáneo, críticas de arte en prensa escrita y mujeres artistas representadas en los museos de España. Fuente: Centro de Documentación de Mujeres en las Artes Visuales. Elaboración propia. 
Desde hace algunos años, la Asociación MAV -Mujeres en las Artes Visualeselabora un informe que analiza la presencia de las mujeres artistas en la feria de arte ARCO. De una lectura somera del Informe MAV se deprende un primer dato esencial: la participación de mujeres artistas en ARCO 2018 es del 25\% sobre el total de artistas expuestos. No obstante, la edición de ARCO 2018 sirvió para evidenciar el problema que tratamos, al menos desde iniciativas externas a la propia organización. "¿2Me estás viendo? Pensaba que al ser mujer y artista no se me ve» fue una frase repetida el día de la inauguración gracias a la iniciativa de las artistas Yolanda Domínguez y María Gimeno que fue secundada por 60 artistas (como Mima Kahlo o Marisa González, de la junta de MAV) que se pasearon por la jornada inaugural de la feria de arte contemporáneo con un localizador rojo como el de Google Maps sobre la cabeza. Bajo el lema \#estamosaquí invadieron el recinto madrileño para denunciar la falta de presencia femenina en el arte [Fig. 2]. Domínguez y Gimeno usaron las redes sociales para buscar artistas que se unieran a su acción y después de un primer llamamiento por Twitter, el boca a boca hizo el resto. Su acción, además, terminó de completarse gracias al hashtag \#estamosaquí de Instagram, con el que artistas y estudiantes de arte se sumaron a la acción compartiendo fotos en redes sociales.

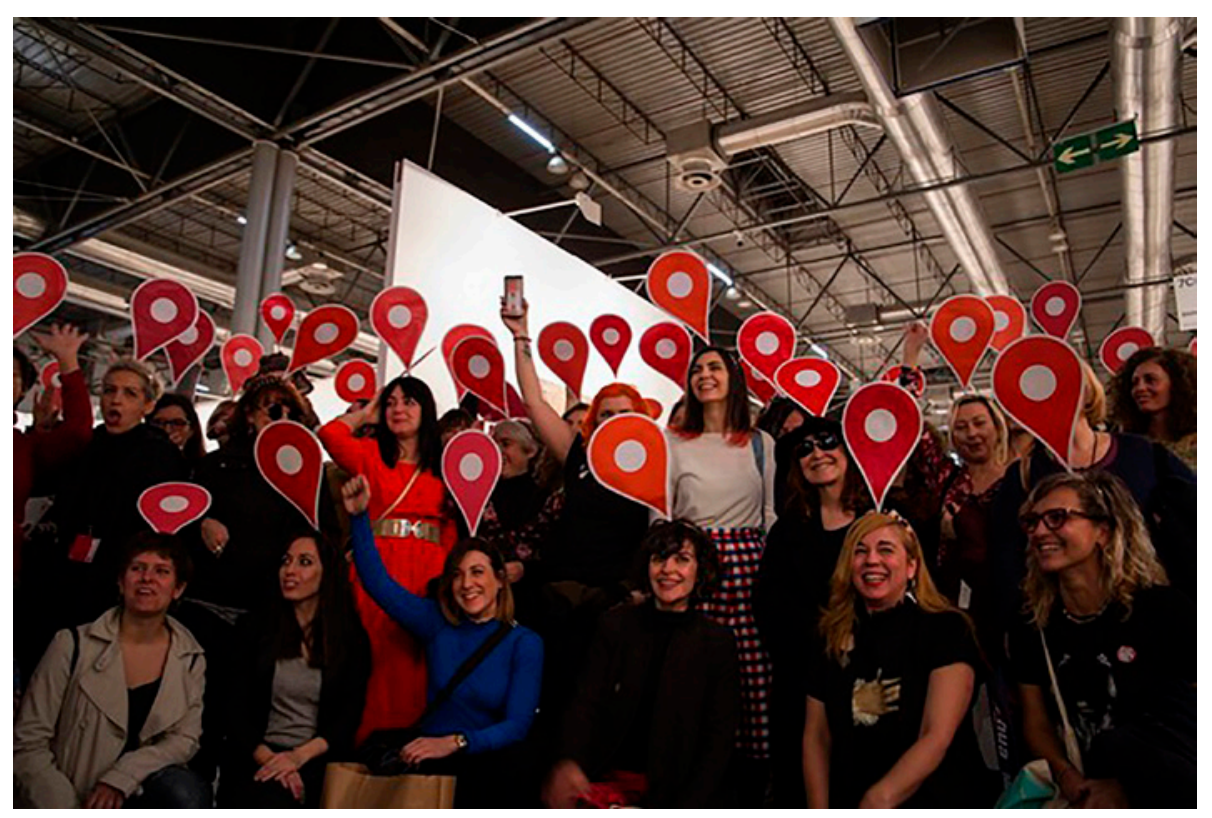

Fig. 2. Acción \#estamosaquí de Yolanda Domínguez en ARCO 2018. Fotografía: Carlos Pina, Huffingtonpost. 
Paralelamente, la artista Verónica Ruth Frías llevó a Arco 2018 su performance I am a woman, de la mano de la Fundación de Artes Plásticas Rafael Botí, la que sin duda ly con permiso de la mediática retirada de la obra de Santiago Sierra antes de la inauguración) fue lo más fotografiado y comentado de esta edición [Fig. 3]. Pink Power, una instalación y I am a woman, la acción recuperaban las ya históricas reivindicaciones feministas, la necesidad de nombrar a las artistas bajo la obligación de no olvidar para no ser olvidadas. Mediante el enunciado, Verónica Ruth propuso un ejercicio de representación aparentemente sencillo pero de gran efecto sobre el espacio real: visibilizar los múltiples significados del ser mujer y recordar que siempre estuvieron aquí. ARCO 2018 giraba en torno a la idea del tiempo futuro, pero sigue obviando las urgencias del presente, entre ellas las que tienen que ver con la igualdad, la educación y también con la exclusión de las mujeres.

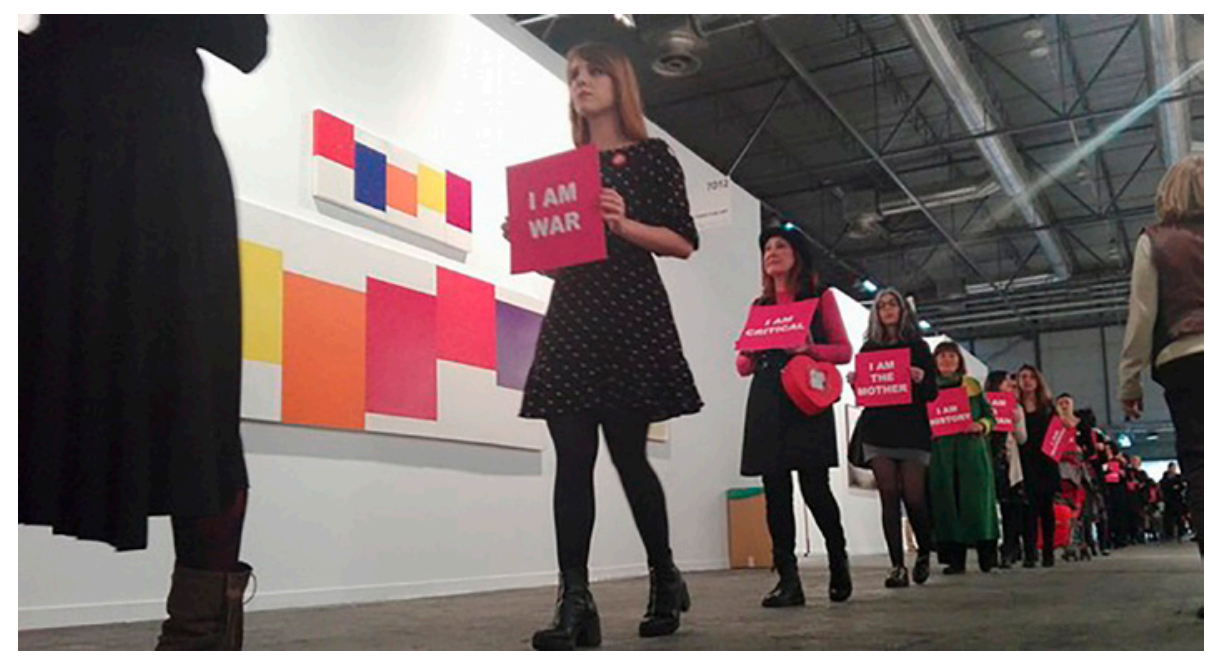

Fig. 3. Acción I am a woman de Verónica Ruth en ARCO 2018. Fotografía: Fundación Botín.

$\dot{\iota}^{A}$ qué se debe esta minúscula presencia femenina en las ferias? No estamos de acuerdo en la común explicación que recurre a que las artes plásticas tienen una tradición masculina (Nochlin, 1971). Pamela Tomás lo plantea con esta interpelación:

El mundo del arte siempre ha tenido una visión androcéntrica en la que, por supuesto, mandaban ellos. Pensad por un momento ¿̇A cuántos artistas puedes nombrar? $Y$ ¿̇ cuántas artistas? Me arriesgo a que no has pasado de Frida Kahlo o Camille Claudel (Tomás, 2018). 
Ciertamente, en la historia del arte son anecdóticas las mujeres que aparecen, pero en las ferias de arte contemporáneo no suelen exponerse producciones del siglo XIX, por ejemplo. No nos vale, por tanto, la excusa de la historia para un evento que se caracteriza por su coetaneidad.

Lo cierto es que existe una discriminación en la relación laboral entre artista y galerista. Una galería se preocupa de que el artista que representa se mantenga activo trabajando, y muchas mujeres interrumpen el proceso. Encontramos aquí la primera causa del problema de la baja representación de mujeres artistas, la garantía de continuidad que busca una galería que quiere vender la posible revalorización de una obra en el tiempo, aunque, naturalmente existen excepciones y grandes complicidades en determinadas relaciones [Fig. 4].

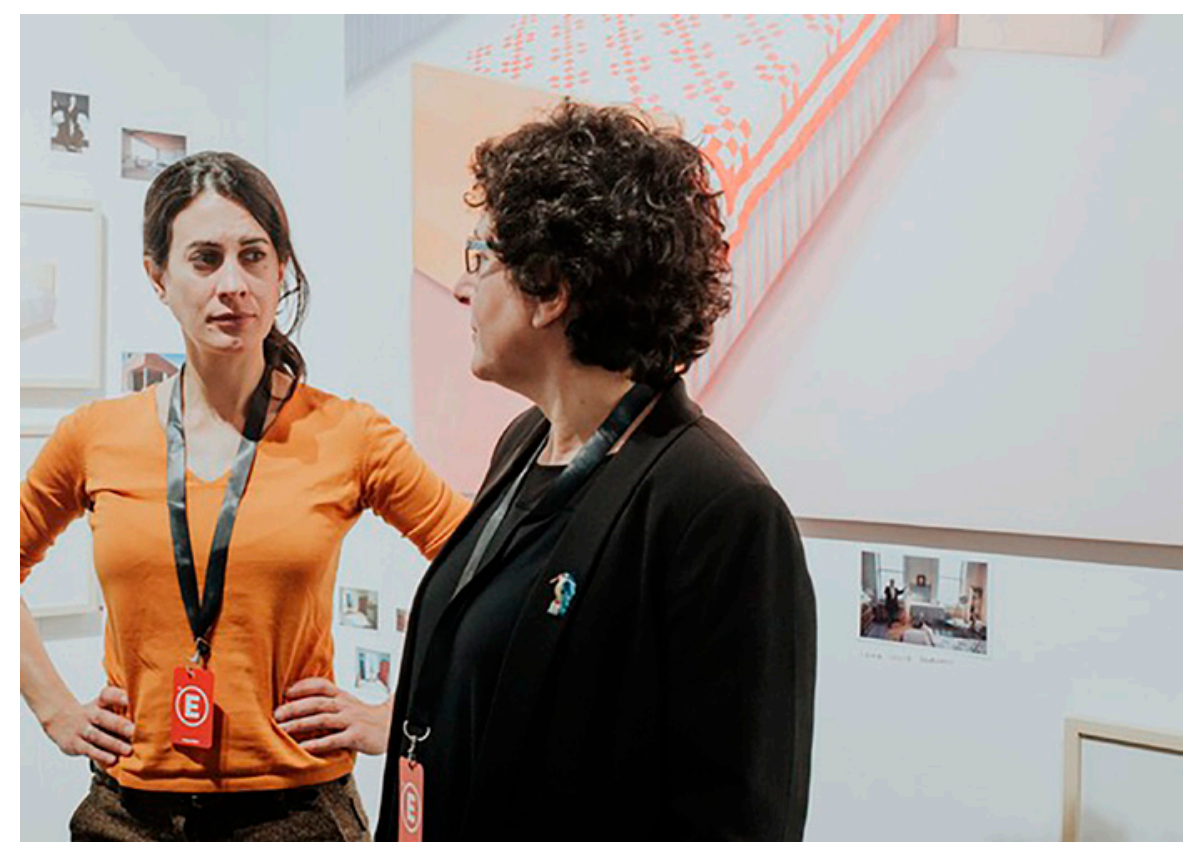

Fig. 4. La artista Teresa Moro (derecha) junto a la su galerista (Espacio Líquido) en Marte 2017. Fotografía: Marcos Amuedo.

Es fácil pensar en la maternidad como primera razón del abandono de una 116 carrera profesional, pero lo cierto es que las artistas jóvenes se desvían hacia otros 
procesos creativos fuera de las artes visuales en mayor medida que los hombres. En los primeros cinco años después de la universidad muchas graduadas se acaban dedicando al diseño, la publicidad o la docencia, probablemente porque sean también los mejores expedientes (de nuevo mayoritariamente de mujeres) los que encuentran una salida laboral más rápida y segura, en un sector ahogado por una precariedad crónica que hace que solamente un $15 \%$ de artistas (hombres y mujeres) puedan vivir de su trabajo (Pérez lbáñez \& López Aparicio, 2017). Esto provoca sólidos prejuicios en la mente de los potenciales compradores de arte que prefieren no adquirir obras de mujeres porque a largo plazo sus carreras no tendrán la duración necesaria o la misma firmeza del inicio. Pocos arriesgan a la hora de invertir en la compra de obras de arte en un contexto especulativo en que el arte masculino, a día de hoy, se continúa percibiendo como un valor más seguro. Además, según la base de datos de Arteinformado, del total de 284 coleccionistas que tienen registrados, solo 37 son mujeres, frente a 133 hombres (el resto, 114 son entidades corporativas). En porcentajes: un 13\%, frente a un $47 \%$ hombres y un $40 \%$ de entidades corporativas (Cao, 2000).

En segundo lugar, no olvidemos que la industria cultural española es una pirámide de poder con una estructura muy definida donde los puestos de mando están copados casi exclusivamente por hombres. La mayoría de los directores de ferias (igual que de las principales pinacotecas) son hombres. Al igual que hay muchas más graduadas en Derecho que graduados, pero apenas mujeres en los altos tribunales, en el arte, se reproduce un techo de cristal a partir de los 35 años, cuando se visualiza la penalización, como en el resto de profesiones, del rol social de la mujer.

$Y$, en tercer lugar, y consecuencia de las dos causas primeras, está el mercado. Evidentemente lo dicho anteriormente es así, porque las reglas del mercado son así, y la continuidad y visibilidad en la industria cultural son básicas para entrar en él. No cabe duda de que en el arte contemporáneo actual el mercado tiene un protagonismo muy importante, y éste premia a los artistas que tienen una carrera, sino más consolidada, sí más continuada, precisamente por haber expuesto determinadas veces en museos y centros, y por trabajar con determinadas galerías que acuden a ferias de arte (Freeman, 1984).

Invitamos a volver al primer párrafo de este texto y releer el artículo de la Ley de lgualdad. Si las reglas del mercado impiden manifiestamente la presencia de mujeres artistas en las ferias de arte se les está negando la posibilidad de estar representadas y de ser reconocidas (y recompensadas) por su trabajo [Fig. 5]. 


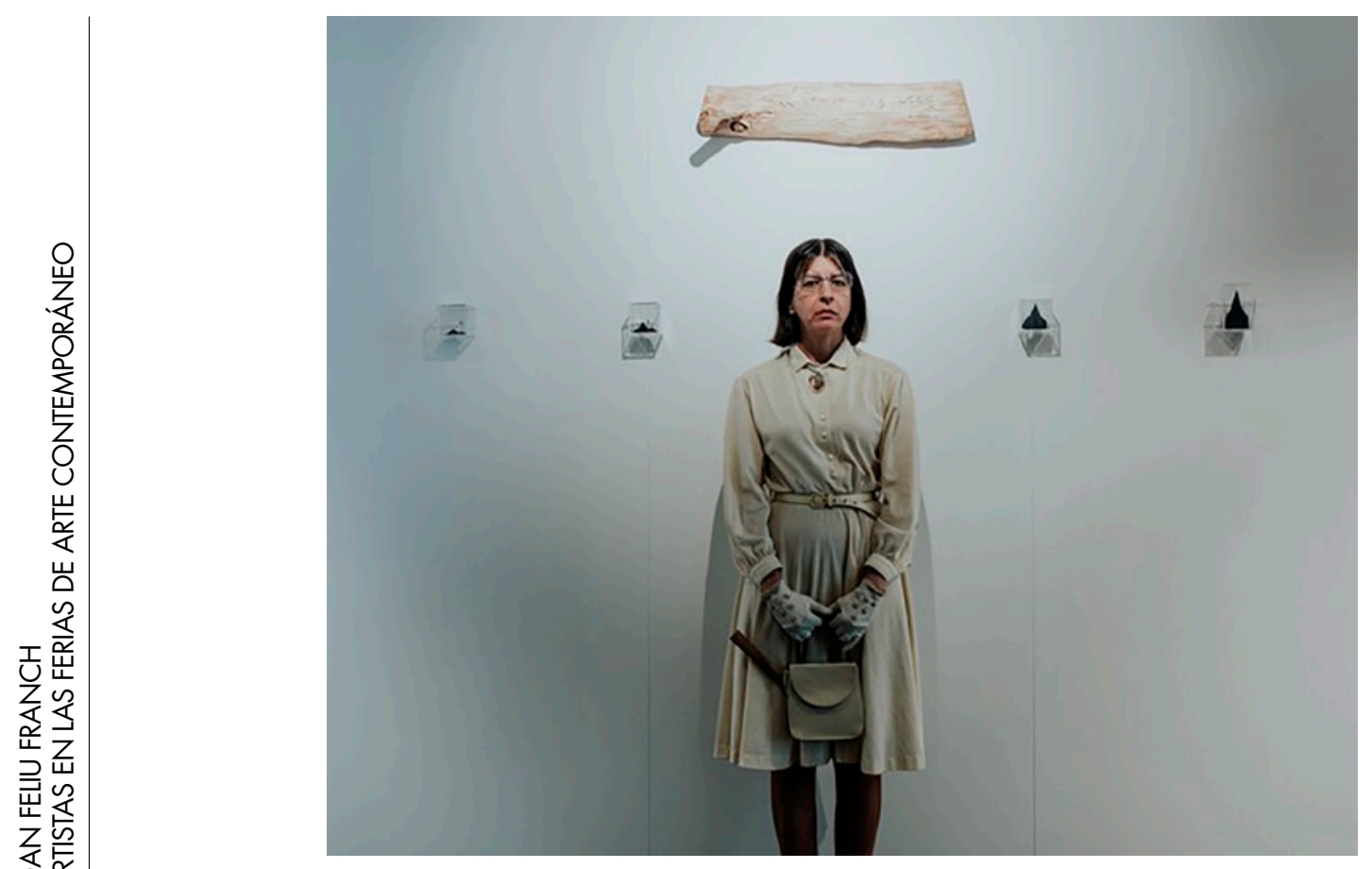

Fig.5. Miss Beige, personaje interpretado por Anna Esmith, que denuncia la dictadura de la imagen en el mercado del arte. Marte 2017. Foto: Marcos Amuedo.

En los últimos 15 años las ventas de arte contemporáneo han crecido en el mundo un $1200 \%$ (Ehrmann, 2017). No hace mucho se vendió un cuadro pintado por Leonardo da Vinci hace cinco siglos, Salvator Mundi, que se ha convertido en la obra más cara de la historia. La casa Christie's la subastó por 450,3 millones de dólares (382 millones de euros), el precio más alto logrado hasta ahora por una obra que llega a una puja pública. En comparación, la obra más cara de una mujer artista se vendió por 44 millones de dólares, la pintura White Flower, N¹ (1936) de Georgia O'keeffe, subastada en Sotheby's en 2014.

Naturalmente no es objetivo equiparar a Leonardo da Vinci con O'keeffe, ni por época, ni por cantidad de obras a la venta. Hablemos entonces de artistas contemporáneos. La parte primordial del mercado del arte se centra en el espacio geográfico europeo, norteamericano y chino. Según los informes de Artprice más de la mitad de los ingresos de arte contemporáneo dependen de tan solo 10 artistas: Jean-Michel Basquiat (1960-1988), 
Christopher Wool (1955), Jeff Koons (1955), Peter Doig (1959), Martin Kippenberger (19531997), Rudolf Stingel (1956), Richard Prince (1949), Damien Hirst (1965), Yoshitomo Nara (1959), Zeng Fanzhi (1964). Como podemos apreciar, los líderes del arte contemporáneo son todos hombres, siendo sus nacionalidades, mayormente, europeas y norteamericanas.

Un indicador importante para revelar la carga femenina en la escena artística es el porcentaje de mujeres artistas frente a hombres en las listas de relevancia. En Artprice, por ejemplo, la posición de un artista en la lista se mide con diferentes instrumentos: el ingreso total del artista en ventas en subastas, la adjudicación máxima de una obra vendida y el alcance del umbral de un millón de euros por adjudicación de una obra. Sin embargo, consideramos más reveladores los llamados Top100 y Top500 que se organizan por la cantidad total que ha ingresado el artista en una temporada de subastas, sin tener en cuenta su adjudicación máxima. Si analizamos, por un lado, el porcentaje de las mujeres artistas en el Top 100 y el Top500, la presencia femenina en el primero es menor que en el segundo. Es decir, los ingresos totales normalmente son menores entre mujeres y por eso muy pocas entran al Top 100. La mayoría de las artistas ocupan las últimas posiciones del Top500. Si hacemos una media de precios de venta entre hombres y mujeres del Top 100, es decir, entre los artistas más cotizados, encontramos que, en una temporada de subastas, un artista masculino de esta privilegiada lista vendría a vender por unos 38 millones de euros, mientras que una artista femenina apenas alcanzaría los 3 millones de euros. De hecho, las adjudicaciones máximas de los hombres artistas son diez veces más altas que las de las mujeres [Gráf. 3].

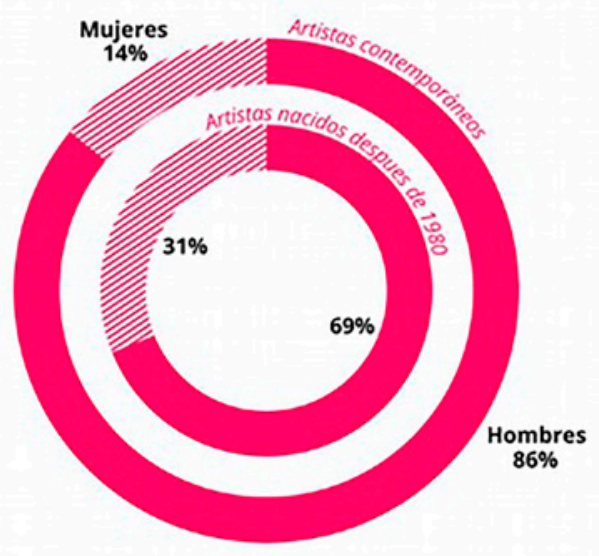

Gráfica 3. Reparto por sexo de los artistas en el Top 500. Fuente: Art Price. 
Analicemos ahora el número de artistas contemporáneos cuya obra ha alcanzado una adjudicación de más de un millón de euros. Reduciendo el espectro únicamente a artistas vivos, naturalmente de diferentes generaciones, resultan 14 mujeres frente a 163. Ese es el paisaje que dibuja el mercado, únicamente un $8 \%$ de artistas mujeres entre las más vendidas. Naturalmente son datos en constante evolución, por lo que citar nombres no es importante, aunque sí cabe señalar que no hay ni una sola artista española entre las más cotizadas del mundo: Marlène Dumas (1953), Rosemarie Trockel (1952), Cecily Brown (1969), Jenny Saville (1970), Julie Mehretu (1970), Cindy Sherman (1954), Elizabeth Peyton (1965), Tauba Auerbach (1981), Beatriz Milhazes (1960), Adriana Varejao (1964)...

Si afinamos todavía más y buscamos artistas jóvenes (por debajo de los cuarenta años) entre los de mayor cotización, nos aparecen nombres como Tauba Auerbach (1981), Lucien Smith (1989), Alex Israel (1982), Óscar Murillo (1986), David Ostrowski (1981), Jacob Kassay (1984), Israel Lund (1980), Dan Rees (1982) y Parker Ito (1986). Todos residen en los Estados Unidos o en el Reino Unido, los dos emplazamientos clave del mercado occidental. De estos nueve artistas, solo la primera es mujer.

Pese a que no existe un estudio completo sobre la presencia de las mujeres en los ámbitos artísticos y museísticos, es relevante que, de los 61 Premios Nacionales de Artes Plásticas, sólo 11 de ellos se hayan concedido a mujeres: Carola Torres (1980), Carmen Laffón (1982),

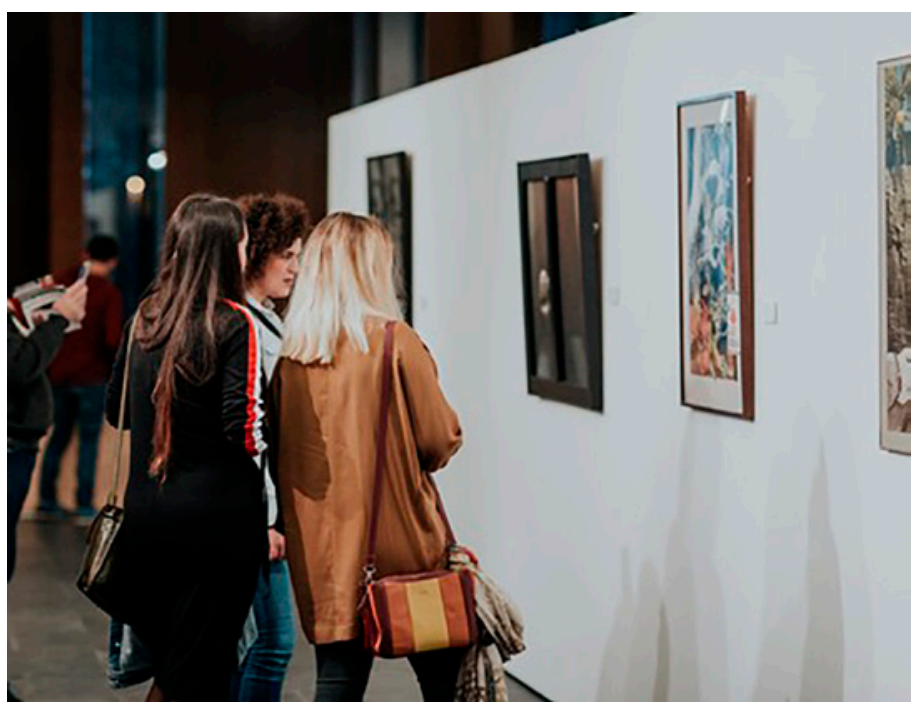

Fig.6. El MACVAC expuso en Marte 2017 obras de Concha Jerez y Juana Francés. Foto: Marcos Amuedo.
Susana Solano (1988), Soledad Sevilla (1993), Eva Lootz (1994), Cristina Iglesias (1999), Esther Ferrer (2008), Elena Asins (2011), Carmen Calvo (2013), Concha Jerez (2015) y Ángela de la Cruz (2017). La misma cifra se desprende de las Premios Nacionales de Fotografía que sólo ha reconocido el trabajo de Cristina García Rodero (1996), Ouka Lele (2005), María Bleda (2008) e Isabel Muñoz (2016). El Premio Velázquez de Artes Plásticas convocado anualmente desde 
el año 2002 sólo ha otorgado un galardón a cuatro mujeres artistas: Doris Salcedo (2008), Esther Ferrer (2014), Marta Minujín (2016) y Concha Jerez (2017); y de los Premios Princesa de Asturias de las Artes ninguno ha recaído en una mujer artista (exceptuando la disciplina teatral y musical) [Fig. 6].

Otro dato que puede parecer anecdótico pero que refuerza esta hipótesis: escasean en las ferias las obras en video, porque son un soporte de venta difícil, pero curiosamente en este formato las mujeres artistas son mayoría. Facilidad de movilidad y bajo coste de producción, hacen que sea una apuesta barata, casi decorativa para muchos stands, sin riesgo. La conclusión es obvia.

Hablando del duro mercado, ¿̇cómo podemos criticar a una galería que como negocio privado toma unas decisiones determinadas atendiendo a mejorar sus ganancias? No lo hagamos. Pero las ferias son otra cosa. Porque muchas de ellas se mantienen gracias al dinero público. Releamos las primeras líneas de este artículo otra vez, por favor: «Las autoridades públicas, en el ámbito de sus competencias, velarán por hacer efectivo el principio de igualdad de trato y de oportunidades entre mujeres y hombres en todo lo concerniente a la creación y producción artística e intelectual y a la difusión de la misma».

Dicha ley propone a los distintos organismos, agencias y administraciones públicas, que gestionan el patrimonio cultural de un modo directo o indirecto, el desarrollo de las siguientes actuaciones para garantizar la igualdad en la creación y difusión intelectual y artística: adoptar iniciativas destinadas a favorecer la promoción específica de las mujeres en la cultura y a combatir su discriminación estructural; elaborar políticas activas de ayuda a la creación y producción artística e intelectual de las mujeres con el objeto de crear las condiciones para que se favorezca la efectiva igualdad de oportunidades; promover la presencia equilibrada de mujeres y hombres en la oferta artística y cultural pública; que se respete y se garantice la representación equilibrada en los distintos órganos consultivos, científicos y de decisión existentes en el organigrama artístico y cultural; y adoptar medidas de acción positiva a la creación y producción artística e intelectual de las mujeres propiciando el intercambio cultural, intelectual y artístico y la suscripción de convenios con los organismos competentes. El dinero público en cualquier acción requiere de una decidida manifestación política por hacer justicia. Los modos de hacer del mercado no pueden ser los que tomemos como referencia, en este caso, pues lo público tiene un compromiso por promover una cultura que sea igualitaria, justa y también realista.

Es tremendamente preocupante la naturalidad con la que se asume la ausencia de las mujeres de la cultura, incurriendo en una doble discriminación, pues sus creaciones son invisibilizadas en los espacios públicos y dichas ausencias a su vez resultan imperceptibles. Es necesario, por tanto, una reestructuración de los fondos, de los discursos expositivos y de las políticas culturales, que posibiliten la inclusión del trabajo creativo de las mujeres, su 
protagonismo como parte de la historia y la cultura. Precisamente éste es uno de los argumentos fundamentales del trabajo de algunas de las principales artistas del panorama nacional [Fig. 7].

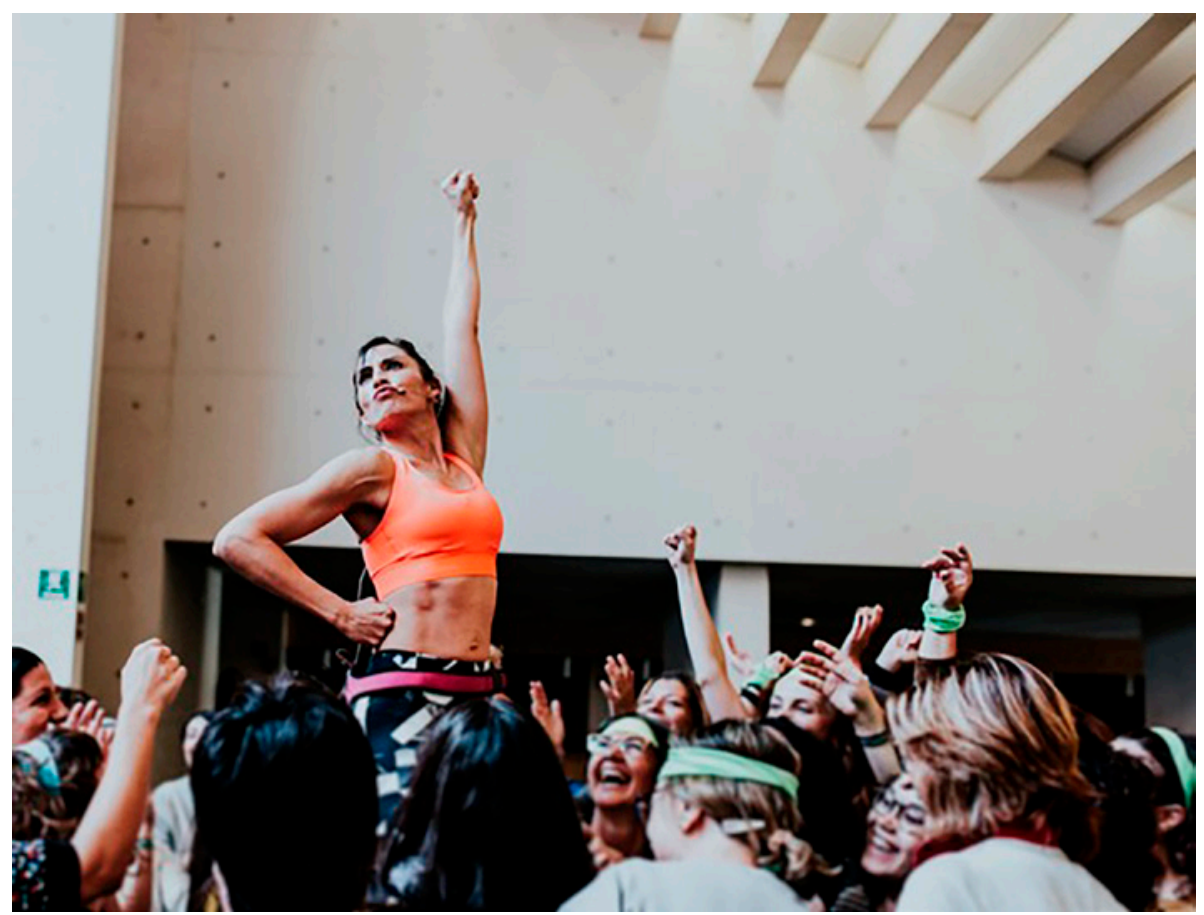

Fig. 7. Acción participativa de Yolanda Domínguez sobre el empoderamiento de la mujer. Marte 2017. Foto: Marcos Amuedo.

Como viene a decir Yolanda Beteta, la deconstrucción de la epistemología museística y del canon artístico para incorporar la perspectiva de género es un proceso vasto y complejo que los museos, galerías y ferias de arte no pueden realizar en solitario. Es una deconstrucción que exige la participación de todos los actores sociales, políticos y educativos, sabiendo que los resultados no serán visibles a corto plazo:

La construcción de una sociedad plural requiere de la deconstrucción de los dogmas patriarcales y del desarrollo de nuevas construcciones socioculturales basadas en el derecho a la igualdad y al reconocimiento de los individuos en el pasado y el presente, en el orden real y en el simbólico de la colectividad con independencia del sexo de los individuos. En el contexto artístico, la concreción de dicha deconstrucción reclama nuevas conceptualizaciones 
que orienten la convergencia reflexiva mediante principios que naturalicen la igualdad y la consiguiente superación de los estereotipos de género que han provocado conductas e identidades excluyentes, androcéntricas y profundamente jerárquicas (Beteta, 2013).

En este contexto, la estructura de una feria como Marte, en Castellón (con cuyas imágenes hemos ilustrado este texto), permite hacer una política efectiva de visualización de la mujer artista [Graf. 4].

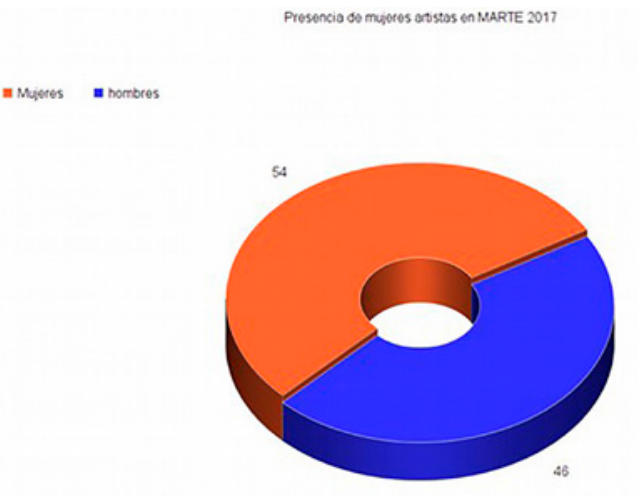

Gráfica 4. Presencia de mujeres artistas en MARTE 2017. Fuente: Elaboración propia.

Marte se ha consolidado en el ámbito del arte contemporáneo español postulándose como una feria totalmente comisariada, lo que constituye hoy en día su seña de identidad. Esta elección de artistas, en una feria que tiene participación de dinero público (como ARCO - Art Madrid) obliga a buscar una paridad en las propuestas. Desde su nacimiento Marte ha optado por un tratamiento igualitario con respecto a la participación de los y las artistas. Y es que, si se pretende ser un reflejo de las mejores manifestaciones artísticas que hoy en día se producen, la paridad se convierte en una característica esencial de la realidad y en el fruto del compromiso con el arte y los desarrollos creativos que estamos viviendo en la actualidad.

Tras Marte, como se ha señalado, otras ferias han continuado en la búsqueda de la consecución de este objetivo, como es el caso de JustMad o Hybrid. En todos los casos se trata de una decisión política tomada por la dirección. Evidentemente, la composición del comité ejecutivo es solo uno de los elementos que pueden influir en los resultados finales, Pero, a la luz de las correspondencias en las ferias aquí analizadas, parece que no es un dato a pasar por alto. 


\section{REFERENCIAS BIBLIOGRÁFICAS}

BATISTA, Arianni (2013). Arte contemporáneo en Ecuador: la producción femenina en la configuración de la escena (1990-2012). Quito, Ecuador: Tesis de Maestría, Facultad Latinoamericana de Ciencias Sociales, p. 158.

Bernárdez, Asunción; Fernández, Antonia \& Marián López F. CaO (2012). El protagonismo de las mujeres en los museos. Madrid: Fundamentos, pp. 12-18.

Beteta Martín, Yolanda (2013). «El desafío de las artistas contemporáneas. Una aproximación a la presencia de las creadoras en las ferias de arte contemporáneo. El caso de ARCO». En Investigaciones Feministas, vol. 4,. Madrid: Universidad Complutense, pp. 49-65.

CAO, Marián L.F. (coord.) (2000). «La creación artística: un difícil sustantivo femenino»". En Creación artística y mujeres. Madrid: Narcea, pp. 13-47.

EHRMANN, Thierry (2017). «Informe anual del mercado del arte contemporáneo en el mundo, 2017». En ArtMarketInsight, Artprice.com, pp. 1-8.

Freeman, R. (1984). Strategic management. Boston: Pitman, pp. 83-84.

Mujeres en las Artes Visuales. Informes de MAV. http://www.mav.org.es/index.php.

MAYAYO, Patricia (2010) « ¿ Hacia una normalización? El papel de las mujeres en el sistema del arte español». En RAMíreZ, Juan Antonio (ed.) (2010). El sistema del arte en España, Madrid: Cátedra, pp. 306-307.

NoCHIN, Linda (1971) «¿̇Por qué no han existido grandes artistas mujeres?», en REIMAN, Karen e Inda SAEZ (2007). Crítica feminista en la teoría e historia del arte, México: Universidad lberoamericana/UNAM, pp. 17-44.

Parker, Rozsika. y Griselda Pollock (1981). Old Mistresses: Women, Art and Ideology, London. UK: Routledge \& Kegan, pp. 150-184.

Pérez lbáñez, Marta e Isidro López Aparicio (2017). La Actividad Económica de los/las Artistas en España, Granada: Fundación Nebrija y Universidad de Granada, p. 63.

Tomás, Pamela (2018). «El techo de cristal de las mujeres en el arte», en Revista Kalós, publicado el 11/03/2018 http://www.revistakalos.com/techo-cristal-mujeres-arte/

TRASFORINI, Antonietta (2009). Bajo el signo de las artistas: mujeres, profesiones de arte y modernidad. Valencia: Publicaciones de la Universidad de Valencia (PUV), pp. 287-291.

124

Recibido el 25 de abril de 2018

Aceptado el 14 de junio de 2018

BIBLID [1 139-1219 (2018) 32: $111-124]$

Dossiers Feministes, 23, 2018, 11 1-124 - ISSN: $1139-1219$ - DOI: http://dx.doi.org/10.6035/Dossiers.2018.23.7 